\title{
Os primeiros tempos da pesquisa em sociologia da educação na USP
}

Celso de Rui Beisiegel

\section{Resumo}

0 artigo fundamenta-se na participação do autor como aluno de graduação e pós-graduação no curso de Ciências Sociais da antiga Faculdade de Filosofia, Ciências e Letras da Universidade de São Paulo (FFCL-USP). Considera também informações e experiências por ele acumuladas como pesquisador do Centro Regional de Pesquisas Educacionais (CRPE) de São Paulo (a partir de 1957) e como professor da disciplina Sociologia da Educação, após a criação da Faculdade de Educação no âmbito da reforma universitária de 1970. Situa a importância da visão de conjunto dos problemas colocados à disciplina no livro Sociologia educacional, concluído em 1940 por Fernando de Azevedo, e encontra em Florestan Fernandes e, especialmente, em Antonio Candido os pontos de partida para a investigação sistemática da educação sob uma perspectiva sociológica. Nesse sentido, o autor apresenta os primeiros trabalhos de Luiz Pereira, hoje clássicos na disciplina, como admiravelmente embasados nas orientações então encontradas em seus mestres Antonio Candido e Florestan Fernandes. Em seguida, examina a crescente ampliação do número de pesquisadores e das bases institucionais de promoção da pesquisa em sociologia da educação, ampliação esta que sugere amplo elenco de questões sobre a situação atual da investigação sociológica no campo da educação.

\section{Palavras-chave}

Sociologia da educação - Origens da pesquisa - FFCL-USP e FEUSP. 


\title{
The early period of research in sociology of education at USP
}

Celso de Rui Beisiegel'

\begin{abstract}
The article draws from the author's experience as an undergraduate and later as a graduate student of the course on Social Sciences at the old Faculty of Philosophy, Sciences and Letters of the University of São Paulo (FFCL-USP). It also incorporates information and experiences accumulated as a researcher at the Regional Center for Education Research (CRPE) in São Paulo (from 1957 onwards) and as a professor in the discipline of Sociology of Education after the establishment of the Faculty of Education within the scope of the 1970 university reform. It situates the importance of the group overview about the problems posed to this discipline by Fernando de Azevedo in his 1940 book Sociologia Educacional (Educational Sociology), and finds in Florestan Fernandes, and especially in Antonio Candido, the starting points of the systematic investigation of education under a sociological perspective. In this sense, the author describes the first works by Luiz Pereira, today classics of the discipline, as admirably grounded in the guidelines then found in his mentors Antonio Candido and Florestan Fernandes. Next, the text examines the expansion in the number of researchers and institutional support to the research in the sociology of education, an expansion that raises a wide range of issues on the current situation of the sociological investigation of the field of education.
\end{abstract}

\section{Keywords}

Sociology of education - Origins of research - FFCL-USP and FEUSP.

I- Universidade de São Paulo, São Paulo,

SP, Brazil.

Contact: beisieg@usp.br 


\section{Apresentação}

Kimi Aparecida Tomizaki"

No ano de 2012, a área de Sociologia da Educação do Programa de Pós-Graduação em Educação da Faculdade de Educação da Universidade de São Paulo (FEUSP), tendo em vista adensar o debate acadêmico entre seus pesquisadores, tomou a decisão de iniciar uma série de seminários de pesquisa sobre diferentes temas a serem abordados por seus próprios docentes. Para dar início aos debates, pareceu-nos uma excelente opção abordar justamente o processo de constituição do campo da sociologia da educação no Brasil, em especial, na Universidade de São Paulo. Certamente, ninguém poderia fazê-lo melhor do que o Prof. Celso de Rui Beisiegel - primeiro professor de Sociologia da Educação na FEUSP, logo após sua criação -, cuja trajetória poderia estabelecer as conexões, os encontros e os desencontros entre a consolidação da disciplina na Faculdade de Educação e seu surgimento e desenvolvimento na Faculdade de Filosofia da USP.

Celso de Rui Beisiegel é professor emérito da USP, foi diretor da FEUSP e pró-reitor de graduação, além de ser autor de extensa obra sobre sociologia da educação. Graduado em Ciências Sociais pela USP (1958), na mesma Universidade concluiu mestrado em Sociologia (1964), doutorado em Sociologia (1972) e livre-docência em Educação (1981). Atuou na Secretaria de Educação e no Conselho Estadual de Saúde do Estado de São Paulo, bem como no Ministério da Educação e na Fundação do Livro Escolar.

Ao final do processo, o que inicialmente havia sido apenas um convite para um seminário de pesquisa transformou-se, nas mãos do Prof. Celso, em um belíssimo texto que analisa o surgimento da disciplina Sociologia da Educação e, mais do que isso, reflete de maneira crítica e lúcida sobre os principais impasses que a envolvem na atualidade. Restam-nos o aprendizado e o deleite com a experiência desse mestre.

II- Professora de Sociologia na FEUSP, junto ao Departamento de Filosofia e Ciências da Educação (EDF) e ao Programa de Pós-Graduação em Educação. Contato: kimi@usp.br 


\section{Presentation}

Kimi Aparecida Tomizakil
In 2012 the area of Sociology of Education of the Graduate Program in Education of the Faculty of Education of the University of São Paulo (FEUSP), with the purpose of strengthening the academic debate among its researchers, decided to initiate a series of research seminars on various themes to be conducted by its own faculty members. It seemed to us an excellent choice to start the seminars by focusing precisely on the process of constitution of the field of sociology of education in Brazil, and more specifically at the University of São Paulo. Clearly, no one is in a better position to do it than Professor Celso de Rui Beisiegel - first Professor of Sociology of Education at FEUSP, shortly after its establishment -, whose trajectory brings together the connections, the agreements and disagreements from the inception and early development of this discipline in the Faculty of Philosophy of USP until its consolidation at FEUSP.

Celso de Rui Beisiegel is Professor Emeritus of USP, was Dean of FEUSP and Adjunct Rector of Undergraduate Studies of USP, and is the author of numerous works on the sociology of education. A graduate in Social Sciences from USP (1958), he obtained also from USP an MA in Sociology (1964) , a PhD in Sociology (1972), and his livre-docência in Education (1981). He worked at the São Paulo State Secretary for Education and at the São Paulo State Health Council, as well as at the Ministry for Education and in the Fundação do Livro Escolar (Schoolbook Foundation).

By the end of the process, what had started as just an invitation to give a research seminar had been transformed at the hands of Prof. Celso into a beautiful text analyzing the creation of the discipline of Sociology of Education and, more than that, reflecting critically and lucidly on the main dilemmas confronting it today. It leaves to us the learning and the delight with the experience of this master of his discipline.

II- Assistant Professor of Sociology at Faculdade de Educação da Universidade de São Paulo, Department of Philosophy and Sciences of Education (EDF), and Graduate Program in Education.

Contact:kimi@usp.br 


\section{Os primeiros tempos da pesquisa em sociologia da educação na USP}

Apresento, em seguida, algumas informações e reflexões registradas a fim de atender ao convite das professoras Flávia Schilling e Kimi Tomizaki para iniciar uma série de diálogos sobre a pesquisa em sociologia da educação na Faculdade de Educação da Universidade de São Paulo (FEUSP). Começo pela delimitação da abrangência destas observações. Não realizei pesquisas sistemáticas sobre o objeto da exposição. Apresento somente resultados de impressões colhidas ao longo de minha passagem pela Faculdade de Filosofia, Ciências e Letras da Universidade de São Paulo (FFCLUSP) e pela Divisão de Estudos Sociais do Centro Regional de Pesquisas Educacionais de São Paulo, nas décadas de 1950 e 1960. Fui aluno de Fernando de Azevedo, Antonio Candido e Florestan Fernandes no curso de graduação em Ciências Sociais. Durante algum tempo, trabalhei como pesquisador junto ao Centro de Sociologia Industrial e do Trabalho (CESIT), na Cadeira de Sociologia I, e depois colaborei com Florestan Fernandes no ensino de disciplinas de sociologia da educação em cursos ministrados no Centro Regional de Pesquisas Educacionais de São Paulo, nos primeiros anos da década de 1960. Acompanhei as andanças de Florestan Fernandes na Campanha de Defesa da Escola Pública e participei de atividades de pesquisa de Luiz Pereira na elaboração de seus estudos de mestrado e doutorado. Conversei com alguns colegas sobre os estudos de sociologia educacional nos primeiros tempos de seu ensino no curso de Pedagogia da antiga FFCL.

Há algum tempo, diante de uma pergunta sobre os principais marcos de nossa disciplina, afırmei ser difícil responder a uma questão formulada assim, de modo tão amplo. Para estreitar o campo de inevitáveis esquecimentos ou injustiças, em resposta à questão, tomei como ponto de partida os primeiros tempos dos trabalhos da disciplina na FFCL da USP. Afirmei en- tão que, sob esse parâmetro, nenhuma reflexão sobre o desenvolvimento da disciplina poderia ignorar os estudos de Fernando de Azevedo e de seus primeiros assistentes, Antonio Candido e Florestan Fernandes. Certamente se definem, já aqui, uma lacuna e um amplo elenco de temas para investigações sobre a influência dos professores estrangeiros contratados no processo de constituição da Faculdade de Filosofia ou mesmo na formação de outras escolas tradicionais, então envolvidas na criação da Universidade de São Paulo. Convém observar ainda que, no processo de fundamentação de posições, teóricas ou práticas, muitos de nossos antecessores atuaram como importantes precursores da pesquisa no campo das ciências da educação, aí incluída a sociologia da educação. 0 Inquérito sobre a educação pública, realizado em 1926 por Fernando de Azevedo para o jornal $O$ Estado de São Paulo, é um bom exemplo de investigação conduzida com vistas à formulação e à defesa de propostas de intervenção na política educacional. Outro exemplo é o Serviço de Medidas Educacionais criado por Lourenço Filho na administração do ensino do Estado de São Paulo nos primeiros anos da década de 1930. Logo em seguida, em 1937 e 1938, enquanto figura central nas iniciativas do Ministério de Educação e Saúde no Governo da União, Lourenço Filho participou das gestões voltadas para a criação do INEP (Decreto_Lei $\mathrm{n}^{\circ}$ 580, de 30 de julho de 1938). Subdividido nas seções de documentação e intercâmbio, de inquéritos e pesquisas, de psicologia aplicada e de orientação e seleção profissional, o órgão foi importante precursor da institucionalização da pesquisa educacional no país. Há muitos outros exemplos nessa mesma direção. Mas, naqueles primeiros tempos, nos estudos abrangidos no campo da sociologia da educação, seguramente não havia uma tradição de trabalhos que pudessem ser identificados como integrantes de uma prática sistemática de pesquisa científica.

Qualquer reflexão sobre as origens da pesquisa em sociologia da educação entre nós deve considerar os trabalhos de Fernando de 
Azevedo, Antonio Candido, Florestan Fernandes e Luiz Pereira. Por seus estudos sobre a contribuição de Mannheim para a análise sociológica da educação e, depois, sobre os estudantes e a transformação da realidade, bem como pelo trabalho na organização da coletânea de leituras Educação e sociedade (PEREIRA; FORACCHI, 1964), seria justo mencionar também Marialice Mencarini Foracchi. Outros nomes poderiam ser acrescentados, mas, pelo menos sob meu ponto de vista, sem igual contribuição para a conformação inicial dos estudos na área.

O livro Sociologia educacional(AZEVEDO, 1954), concluído em 1940 por Fernando de Azevedo, é um dos marcos significativos na afırmação da disciplina. Embora a obra já esteja quase esquecida, a qualidade de suas dissertações, os desafios apresentados aos leitores, a bibliografia e a sistematização das questões envolvidas no estudo sociológico da educação merecem a atenção dos pesquisadores. No início de sua atividade docente e de pesquisa na FFCL da USP, Florestan Fernandes não cuidava especificamente das questões da educação escolar. É bem verdade que em suas pesquisas sobre os tupinambás encontram-se importantes contribuições para o estudo da educação em sociedades primitivas. Ele também participou nas discussões sobre o ensino da sociologia e envolveu-se nos debates concernentes à criação dos centros de pesquisa educacional do INEP, examinando-os sob a perspectiva da intervenção na realidade social do país. Nessa etapa, porém, sua principal contribuição para a conformação de nosso campo de estudos estava na insistência sobre a necessidade de se compreender a sociologia, aí incluída a sociologia da educação, como ciência a ser rigorosamente construída a partir da metodologia científica. Com Florestan, o discurso anterior sobre questões da educação caminhava inequivocamente para a investigação sociológica empírica das realidades no campo educacional. Naturalmente, a investigação empírica não prescindia da orientação teórica sobre o que, por que e como pesquisar nas realidades sociais na educação. Nos meados da década de 1950, Antonio Candido publicou o estudo intitulado As diferenças entre o campo e cidade e seu significado para a educação (SOUZA, 1957) e o artigo A estrutura da escola (SOUZA, 1964). As preocupações metodológicas de Florestan e as orientações presentes nesses estudos de Antonio Candido constituem-se em espinha dorsal dos primeiros trabalhos de Luiz Pereira. Embora editada alguns anos depois, a coletânea Educação e sociedade, organizada por Luiz Pereira e Marialice Mencarini Foracchi, oferece ampla visão de conjunto sobre questões então focalizadas no ensino e na pesquisa na disciplina.

Algumas lembranças de meus primeiros anos na graduação em Ciências Sociais ajudam a conduzir essas reflexões. Ainda não era o tempo dos estudos em profundidade sobre $O$ capital, de Marx, iniciados após importante seminário realizado por Gianotti, Bento Prado, Fernando Henrique Cardoso, Octavio Ianni, Paul Singer, Roberto Schwarz, Weffort, Fernando Novaes e outros notáveis professores da Universidade. Logo no semestre inicial de meu primeiro ano no curso, em 1955, Ruy Galvão de Andrada Coelho apresentou-nos o livro La vocación actual de la sociologia, de Georges Gurvitch. Em seguida, com Maria Isaura Pereira de Queiroz, lemos Crítica da economia política, de Marx, em edição de 1946 da Editora Flama, com tradução e introdução de Florestan Fernandes (1975). Circulava entre nós a edição doméstica preparada por Aziz Simão (FERNANDES, 1954) das aulas de Florestan sobre os problemas da indução na sociologia. Nas diversas disciplinas de sociologia, antropologia, política, economia política, além de outras, éramos introduzidos aos estudos dos principais autores da sociologia na Europa e também nos Estados Unidos: Marx, Max Weber, Durkheim, Mannheim, Wright Mills, Znaniecki, entre muitos outros. Esse equipamento intelectual marcava as perspectivas de investigação sobre escola e sociedade nos primeiros estudos de sociologia da educação. 


\section{Ampliação dos recursos institucionais da pesquisa em sociologia da educação}

Como será exposto logo em seguida, os primeiros estudos aqui mencionados foram produzidos no âmbito da disciplina Sociologia Educacional, ministrada por professores da Cadeira de Sociologia aos alunos de graduação em Pedagogia. Já os primeiros estudos de Luiz Pereira e o próprio comprometimento maior de Florestan Fernandes com as questões da educação escolar evocam um quadro institucional mais amplo, no âmbito da cooperação que então se estabelecia entre departamentos da FFCL da USP e o INEP, do Ministério da Educação.

0 Centro Regional de Pesquisas Educacionais de São Paulo (CRPE/SP) foi criado em 1956, como parte de um ambicioso projeto de Anísio Teixeira com a intenção explícita de colocar as ciências sociais a serviço da reconstrução educacional do país. Além de um Centro Brasileiro de Pesquisas Educacionais (CBPE), foram criados cinco centros regionais, nos estados de São Paulo, Rio Grande do Sul, Minas Gerais, Bahia e Pernambuco (FERREIRA, 2001). O Centro de São Paulo foi instalado mediante convênio celebrado entre o INEP e a USP, representada pelos departamentos de Pedagogia, Sociologia e Antropologia da FFCL. No âmbito do convênio, competia aos departamentos a indicação do diretor e dos membros do Conselho Administrativo. Na prática, quase todos os pesquisadores eram ou haviam sido vinculados à Faculdade de Filosofia. Sob a perspectiva dos agentes e das instituições então envolvidas, o Centro podia ser visto como uma extensão da Faculdade de Filosofia. Nesse sentido, Márcia dos Santos Ferreira (2001, p. 158) observa que

Florestan Fernandes, em um depoimento em que faz referência à criação do CRPE/ SP, afirma que o Centro "suplementou" a Faculdade de Filosofia e a Universidade nas áreas de atualização de professores e pesquisa científica voltada para a reconstrução educacional do país.

A autora também afirma que, ao justificarem seus projetos de pesquisa, os pesquisadores do Centro

[...] sempre enfatizavam o caráter científico de suas proposições, procurando estabelecer critérios considerados cientificamente válidos através do estudo das teorias psico-pedagógicas e sociológicas em uso no meio acadêmico da época. Essa característica fez com que alguns trabalhos de pesquisa do Centro servissem de ponto de partida para teses acadêmicas que se desenvolveriam mais tarde, na USP. Os trabalhos de Luiz Pereira são um exemplo. (FERREIRA, 2001, p. 158)

Mas, a esse respeito, é importante observar que os trabalhos iniciados no período atendiam a orientações propostas por Anísio Teixeira para a pesquisa educacional na instituição.

0 CRPE/SP contribuiu em muitos sentidos para a expansão da pesquisa educacional: intensificou as relações entre os pesquisadores de São Paulo e de outros estados, sobretudo aqueles igualmente contemplados com a instalação dos centros regionais de pesquisa, ampliou o campo de atuação de intelectuais e pesquisadores já então vinculados ao campo educacional e, ao mesmo tempo, foi importante canal de inserção das questões da educação entre os pesquisadores de outros departamentos da Universidade. Um bom exemplo dessa afırmação está no próprio envolvimento de Florestan Fernandes com as questões da educação, explicável em grande parte pela intensa participação do sociólogo nas discussões que precederam a criação dos centros de pesquisa educacional. Os trabalhos apresentados no Simpósio sobre Problemas Educacionais Brasileiros também exemplificam a afırmação: envolveu-se na discussão sobre a educação e seus problemas na sociedade brasileira um expressivo contingente de intelectuais da Universidade (FERREIRA, 
2001). Naturalmente, nem todos os temas trabalhados incluíam-se numa sociologia educacional, mas o evento atraiu a atenção de investigadores de áreas diversas para a reflexão sobre questões de alguma forma pertinentes à investigação sociológica na educação (VIDAL, 2000). Cabe ainda observar que, por ser inicialmente constituído por jovens, quase todos recém-egressos ou ainda estudantes dos cursos de graduação em Pedagogia, Filosofia e Ciências Sociais da FFCL, o CRPE funcionou como campo de formação e posterior recrutamento de pesquisadores para outras escolas de ensino superior na área educacional. Em 1962, o chefe do Departamento de Pedagogia da FFCL, Laerte Ramos de Carvalho, assumiu concomitantemente a direção do CRPE/SP e, em seguida, promoveu a mudança do curso de Pedagogia para as instalações do Centro, na Cidade Universitária. A partir daí ampliou-se a colaboração entre as duas unidades: pesquisadores do CRPE foram recrutados por diversos setores do Departamento de Pedagogia; professores do Departamento passaram a atuar em atividades das divisões de pesquisa e de aperfeiçoamento do magistério do CRPE; atividades e relações institucionais antes restritas à atuação do CRPE estenderam-se naturalmente aos âmbitos de atuação do pessoal dos departamentos envolvidos. Alguns estudos importantes datam desse período de maior colaboração institucional. Encontra-se um bom exemplo disso nos estudos Educação e desenvolvimento (HAVIGHURST; GOUVEIA, 1969) e Ensino médio e estrutura socioeconômica (DIAS, 1967). 0 posterior ingresso de Aparecida Joly Gouveia na Cadeira de Sociologia II do Departamento de Ciências Sociais da FFCL contribuiu para essa ampliação dos recursos da pesquisa em sociologia da educação na USP.

Outras instituições colaboraram para a ampliação e a diversificação dos estudos no campo da educação, aí incluída a sociologia da educação. Em 1955 foi criado o Instituto Superior de Estudos Brasileiros (ISEB). No desempenho de seu compromisso explícito com a elaboração da ideologia do desenvolvimento nacional, o grupo de intelectuais reunidos no ISEB exerceu papel significativo em estudos realizados no campo educacional. Além de sua influência nos debates sobre a educação, o Instituto promoveu a edição de livros como Ideologia e desenvolvimento nacional (PINTO, 1956), Introdução aos problemas do Brasil (RAMOS, 1956), A redução sociológica (RAMOS, 1958) e Educação não é privilégio (TEIXEIRA, 1957). As construções de Vieira Pinto nessa publicação deram importante contribuição aos primeiros ensaios de sistematização das ideias de Paulo Freire. Nesse final dos anos 1950, a intensa interlocução de Paulo Freire com as análises de intelectuais do Instituto, especialmente Viera Pinto, Guerreiro Ramos, Corbusier e Jaguaribe, chegou a identificá-lo, em alguns círculos, como um educador isebiano (PAIVA, 1973, 1980).

A partir dos anos 1970, a Fundação Carlos Chagas expandiu suas atividades no campo da pesquisa educacional: ampliou consideravelmente as atividades de prestação de serviços na avaliação e na pesquisa, além de reunir um importante grupo de intelectuais e pesquisadores, alguns com passagem anterior ou concomitante na USP, outros contratados posteriormente pela USP ou por outras universidades. ${ }^{1}$ Certamente, a inclusão da FCC e, sobretudo, do ISEB entre os recursos que possibilitaram a expansão da pesquisa em sociologia da educação é aceitável só até certo ponto, pois a própria natureza dessas instituições dificulta a classificação de seus trabalhos em um ou outro dos escaninhos disciplinares vigentes no ensino universitário. Seus trabalhos, porém, enriqueceram o conhecimento disponível sobre a escola e a sociedade.

A expansão do ensino superior ampliou a base institucional de produção da pesquisa em sociologia da educação. Aos trabalhos inicialmente limitados às faculdades de filosofia da capital, especialmente na USP,

1- Mais diretamente vinculados ao campo destas reflexões estão, entre outros, Lólio Lourenço de Oliveira, Vitor Henrique Paro, Maria Helena Souza Patto, Marta Kohl de Oliveira, Claudia Vianna, Guiomar Namo de Mello, Teresa Neubauer da Silva, Celso João Ferretti. 
na Pontifícia Universidade Católica (PUC-SP) e em suas instituições complementares, acrescentaram-se os estudos dos pesquisadores das faculdades de filosofia, ciências e letras progressivamente instaladas no interior paulista a partir da segunda metade da década de 1950. É importante incluir neste item também a criação da Universidade Nacional de Brasília (UnB), no Distrito Federal. Na sequência da interação estabelecida entre o CBPE e os centros regionais, Darcy Ribeiro procurou levar pesquisadores de São Paulo para o corpo docente da Faculdade de Educação que então se constituía na UnB. Após convite não atendido por Luiz Pereira, uma das vagas disponíveis foi ocupada por Perseu Abramo, ex-pesquisador do CRPE. Um pouco depois, com a criação da Universidade Estadual de Campinas (UNICAMP), as possibilidades de estudos e pesquisas em sociologia da educação foram significativamente ampliadas. Deve-se registrar, ainda, os trabalhos efetuados por sociólogos na Fundação Getúlio Vargas (FGV/SP).

No âmbito das mudanças observadas nos recursos institucionais da realização de pesquisas em sociologia da educação é preciso mencionar a reforma da USP em 1970, com a criação da Faculdade de Educação. A disciplina Sociologia da Educação do curso de Pedagogia passou a ser ministrada por docentes da nova unidade, reservando-se para a Faculdade de Filosofia, Letras e Ciências Humanas somente um semestre de estudos em Sociologia Geral. Posteriormente, mesmo esse semestre foi transferido para a Faculdade de Educação. Tal ampliação das atribuições na graduação, somada às novas exigências dos cursos de pós-graduação, explicam o progressivo aumento do quadro de docentes da disciplina, bem como a diversificação e o aprofundamento dos estudos no interior da área. Situação semelhante ocorreu com outros setores da Faculdade, igualmente marcados pela expansão do quadro de professores e pela diversificação dos trabalhos. Atualmente, encontram-se em diferentes setores da Faculdade pesquisadores com formação em Ciências Sociais realizando estudos e pesquisas perfeitamente enquadráveis na área da sociologia da educação.
Cabe observar que, ao longo das últimas décadas, a demarcação de áreas de estudos pelas respectivas disciplinas foi penetrada por recortes alternativos motivados, entre outros fatores, especialmente pelas exigências interdisciplinares dos processos de intervenção na realidade educacional.

\section{Os primeiros trabalhos}

0 ensaio de Antonio Candido sobre As diferenças entre o campo e cidade e o seu significado para a educação remete à tese intitulada Contribuição ao estudo de problemas do ensino rural, apresentada em colaboração com José Querino Ribeiro (1952) ao IV Congresso Normalista de Educação Rural, realizado em São Carlos, em 1951. Em sua versão mais elaborada, o texto foi publicado em 1957 no primeiro número da revista Pesquisa e Planejamento, do Centro Regional de Pesquisas Educacionais de São Paulo. Fundamentava-se, entre outros estudos, em A ideologia alemã, de Marx, em L'homme des révolutions politiques et sociales, de Lefebvre, bem como em análises de Sorokin, Zimmerman e Galpin sobre sociologia rural e urbana (SOUZA, 1957).

0 ensaio começa por afirmar que o século XX, ao contrário dos antecedentes, aceitava as contradições da vida em sociedade.

Hoje sabemos que nem a natureza é um sistema harmônico, nem o homem pode esposar as supostas harmonias para se tornar um ser magicamente adequado ao meio, à sociedade, aos outros homens e a si mesmo. (SOUZA, 1957, p. 52)

Era necessário dar ao educador a consciência de uma realidade marcada por rupturas e contradições, diferente do que afirmavam as teorias assentadas na visão de uma harmonia fundamental do mundo da natureza e de sua extensão ao mundo das normas. 0 processo educativo não seria a promoção de um encontro feliz entre a natureza harmoniosa e a 
razão dócil ao seu ensinamento. Era perigoso desconhecer desarmonias, algumas ligadas à constituição biológica dos indivíduos, outras definidas segundo as normas da vida em sociedade: como exemplos, Antonio Candido aponta o choque entre a idade em que é necessário estudar e os interesses que então predominam entre os estudantes, bem como a tensão entre as gerações e a necessidade de hierarquia na escola. Ele observa que, segundo Lefebvre, seriam três as desigualdades fundamentais no mundo moderno: entre o homem e a mulher; entre as classes sociais (pobres e ricos); entre o citadino e o camponês. Em seguida, identifica nessa última uma das desarmonias da sociedade moderna que necessariamente envolvem a educação:

[...] notadamente a oposição entre campo e cidade como universos culturais e sociais diferentes, gerando dois tipos contraditórios de existência e repercutindo na esfera educacional. (SOUZA, 1957, p. 55)

Antonio Candido atribui a Marx, em $A$ ideologia alemã, a formulação moderna desse problema nos termos do desenvolvimento técnico e dos recursos da análise social.

A oposição entre cidade e campo só pode existir no quadro da propriedade privada. É a mais grosseira expressão da subordinação do indivíduo à divisão do trabalho e a uma atividade que lhe é imposta, uma subordinação que de um faz um animal limitado da cidade; do outro, um animal limitado do campo, reproduzindo diariamente a oposição de seus interesses. (SOUZA, 1957, p. 56-57)

Acompanhando essas indicações de Marx, ele parte da divisão social do trabalho, com a crescente especialização das ocupações e um tipo de ajustamento ecológico que se exprimem na dicotomia campo-cidade como formas diferentes de ocupação do meio e distribuição dos grupos no espaço, caracterizadas por uma crescente diferenciação dos meios de produção e das necessidades. Ao definir as condições de desigualdade na repartição social dos bens e serviços, a propriedade privada explicaria a dicotomia entre campo e cidade: no sentido vertical, ao longo das diferenças de classe; e no sentido da cultura, considerando-se os tipos de ocupação do solo.

Sem falar nas consequências espirituais, manifestas na forte diferença entre o habitante da cidade, potencialmente apto a aproveitar imediatamente os benefícios da civilização e o do campo voltado para formas retrógradas de cultura pelo isolamento e a tradição. (SOUZA, 1957, p. 57-58)

Definem-se dois modos diferentes e contraditórios de participação na vida cultural e social. A sociedade brasileira apresentava forte oposição entre a vida rural e a vida urbana. Essa polaridade era afirmada em termos tipológicos, pois, na realidade, ocorria a interpenetração de aspectos da vida rural nas cidades e uma crescente penetração do urbano na vida rural. Entretanto, o progresso técnico e as modificações em curso na estrutura social indicavam a possibilidade de superar, em grande parte, essa oposição devido à supressão relativa de um dos termos. 0 crescente deslocamento de habitantes do campo para as cidades e a progressiva difusão de técnicas e modos de vida urbanos nas áreas rurais favorecia essa possibilidade de futuro. 0 estudo apontava para o irresistível sentido da urbanização e a consequente supressão do rural. Não se tratava, porém, de uma supressão enquanto vida no campo, mas de uma progressiva eliminação de formas rústicas de vida despojada do acesso aos recursos materiais e culturais proporcionados pela sociedade moderna. Havia resistências à urbanização, expressas em movimentos ruralistas e ideologias de defesa das condições de vida no campo. Encontravam-se expressões dessas ideologias em posições defendidas para o ensino rural, por exemplo, em propostas de formação 
específica do professor rural, vinculado à vida rural e comprometido com a busca de melhor ajustamento dos trabalhadores ao meio. 0 autor concluía perguntando aos educadores em qual sentido entendiam que deveria encaminhar-se a educação do homem do campo.

0 ensaio é admirável e tem contribuições significativas em muitos sentidos. Uma delas será objeto de análise nas observações a propósito da comunicação apresentada por Luiz Pereira no Simpósio sobre Problemas Educacionais Brasileiros, promovido pelo Centro Regional de Pesquisas Educacionais de São Paulo.

0 outro artigo já mencionado de Antonio Candido sobre $A$ estrutura da escola também resultava do esforço de contribuição do sociólogo para os trabalhos do educador. 0 texto começava por assinalar a existência de duas ordens diversas de normas de comportamento na escola.

A estrutura administrativa de uma escola exprime a sua organização no plano consciente, e corresponde a uma ordenação racional, deliberada pelo Poder Público. A estrutura total de uma escola é todavia algo mais amplo, compreendendo não apenas as relações ordenadas conscientemente mas, ainda, as que derivam da sua existência enquanto grupo social. (SOUZA, 1964, p. 107)

Embora deva sua existência à cooperação de seus membros, àqueles que aprendem e aos que ensinam, enquanto grupo social instituido, ${ }^{2}$ a escola tem suas funções coletivas e posições ao menos parcialmente institucionalizadas por outros grupos sociais. Os instituidores (associações religiosas, empresas, agentes particulares em geral, entidades públicas) estabelecem normas com vistas a adequar a atuação das escolas aos seus interesses e às suas finalidades. Antonio Candido adverte que, no Brasil, sobre todas as normas prevalecem as que foram estabelecidas pela legislação.

2 - Antonio Candido remete ao conceito de grupo social instituído na obra de Znaniecki (1947).
Encontram-se aí, nessa atuação dos poderes públicos, os principais fatores de similaridade entre as escolas de um mesmo tipo em todo o território nacional. Assim, sob a perspectiva da racionalidade instituída pelo legislador, todas as escolas de um mesmo tipo poderiam ser vistas como semelhantes. Essa identidade seria ainda reforçada pelas similaridades da própria vida social e pelas tendências comuns da sociabilidade infantil e juvenil. Mas, enquanto produto da cooperação de seus membros, cada grupo social escolar tem na própria dinâmica interna os fatores de possibilidade de sua diferenciação: "A sua dinâmica interna dá lugar a formações específicas, mantidas por um sistema de normas e valores também internamente desenvolvidos" (SOUZA, 1964, p. 109).

0 estudo da estrutura social da escola deveria começar pela observação da sociabilidade interna do agrupamento. Mas não bastava "estudar o desenvolvimento da sociabilidade, desde a formação do sentido do real, até a aquisição de hábitos necessários à vida em sociedade"; era

[...] preciso dar atenção ao que há de específico na sociabilidade da criança e do adolescente em face do adulto; aos tipos de agrupamento por eles desenvolvidos; ao mecanismo de seleção dos líderes; ao conflito com os padrões sociais impostos pela educação, etc. (SOUZA, 1964, p. 110)

Local de acomodação de tensões, especialmente entre os imaturos e os membros adultos (professores e administradores) representantes dos padrões de conduta e expectativas da sociedade, a escola constituiria um ambiente social peculiar: era evidente que as relações entre uma ordenação racional e uma população imatura com problemas específicos de conduta resultariam em diversificação de atitudes, comportamentos, valores. A própria interação entre seus diferentes segmentos constituía-se em um dos fatores de possibilidade de diferenciação entre os grupos sociais escolares. 
Apresentadas essas diretrizes para o estudo da estrutura da escola, o texto avançava em seguida para a análise dos subgrupos identificáveis em seu interior e dos mecanismos de sustentação dos agrupamentos. Propunha o estudo das formas e características dos agrupamentos por idade, sexo, associações espontâneas, status e, enfim, por grupos de ensino, o elemento central na realização das principais finalidades declaradas da escola. Na sequência, traçavam-se questões relevantes ao estudo dos elementos de sustentação dos agrupamentos: a liderança exercida pelo educador e pelo educando; as normas de conduta que regem o comportamento do educador e as que regem o comportamento do educando; o elenco de sanções administrativas, pedagógicas e grupais; e os símbolos, que completam o conjunto de elementos favoráveis à coesão do grupo social. No seu todo, o artigo realmente oferecia aos estudantes um roteiro seguro e fecundo de orientação das investigações sobre a estrutura e o funcionamento dos grupos sociais escolares. Assim como o anterior, A estrutura da escola também foi um texto decisivo na condução das primeiras investigações de Luiz Pereira na sociologia da educação.

\section{Os estudos de Luiz Pereira}

Luiz Pereira foi aluno do curso de graduação em Pedagogia da FFCL da USP entre 1952 e 1955.

Iniciou suas atividades profissionais como professor de sociologia, história da educação, educação social e cívica e história da civilização brasileira em escolas normais particulares na cidade de São Paulo. Entre agosto de1957 e maio de 1959, foi assistente de pesquisa no Centro Regional de Pesquisas Educacionais de São Paulo. Em 1958, iniciou o curso de especialização (mestrado) em sociologia, sob a orientação de Florestan Fernandes. Em maio de 1959, por indicação de
Florestan Fernandes, assumiu a regência da cadeira de Sociologia e Fundamentos Sociológicos da Educação da Faculdade Estadual de Filosofia, Ciências e Letras de Araraquara. Em abril de 1963, transferiuse para a cadeira de Sociologia I da FFCL da USP. (FÁVERO, 2002, p. 731)

É importante registrar que, logo no início de sua vida profissional, lecionou durante cerca de um ano numa escola primária da periferia do município de Santo André, na Grande São Paulo. Essa experiência teria participação decisiva em seus trabalhos de pós-graduação, pois serviu como pesquisa exploratória no desenvolvimento da investigação que apresentou ao final dos estudos de especialização, em 1960, e na tese de doutorado, defendida em 1961.

0 conhecimento proporcionado pela vivência da escola normal onde concluiu os estudos secundários e as atividades profissionais na escola primária estadual em Santo André, bem como as orientações encontradas em Antonio Candido e Florestan Fernandes, estão evidentes nos trabalhos produzidos por Luiz Pereira nesses primeiros tempos de pesquisador.

Convém iniciar o exame dessas evidências pelo estudo sobre Rendimento e deficiências do ensino primário brasileiro (PEREIRA, 1968) relatado por Luiz Pereira no Simpósio sobre Problemas Educacionais Brasileiros. ${ }^{3} \mathrm{Na}$ versão original da comunicação, ele organizou as informações disponíveis sobre evasão escolar e reprovação no Estado de São Paulo, no período de 1935 a 1955, discriminando-as pela localização das escolas segundo áreas urbanas, rurais e distritais. A evasão escolar e a reprovação, entendidas como expressão de deficiências no rendimento do ensino, eram bem maiores no campo do que nas cidades. Os distritos, pequenos agrupamentos urbanos, em geral vinculados ao meio rural, apareciam em posição inter-

3- 0 Simpósio sobre Problemas Educacionais Brasileiros foi um encontro de intelectuais e educadores organizado por Fernando de Azevedo e presidido por Anísio Teixeira no CRPE/SP, em setembro de 1959. 
mediária. Tratava-se, em seguida, de explicar o melhor desempenho diferencial das escolas primárias nas cidades, nos distritos e no campo.

Em fiel cumprimento do roteiro recomendado por Antonio Candido, o estudo começa pelo exame da escola como grupo social internamente diferenciado em subgrupos, com especial atenção ao subgrupo de ensino. Aí, enquanto grupo social instituído, no exercício da função explícita do ensino primário, professores e alunos atuam como comunicadores e receptores de determinada parte da herança sociocultural, composta pelas técnicas elementares da leitura, da escrita e do cálculo, bem como por elementos da chamada cultura geral - ciências físicas, higiene, história, preceitos e valores morais e cívicos, artes etc. Esse conteúdo cultural seria parte

[...] do patrimônio cultural de camadas citadinas sócio-econômicas não inferiores, em estreita ligação com um estilo urbano de vida, vivido especialmente por tais camadas.

Nesse processo, ao mesmo tempo, realizaria também sua função implícita, pois, ao transmitir os conteúdos de um estilo urbano de vida, o subgrupo funcionaria, nas comunidades rurais e semirrurais, como agência de desintegração de um estilo rústico de vida, como agência de urbanização. Essa relação estende-se também aos imensos contingentes da população rural deslocados para as periferias urbanas em busca de empregos e melhores condições de vida.

A atuação do poder público na padronização da estrutura e do funcionamento das escolas primárias está subjacente a toda a análise. A atuação das escolas seria muito semelhante em todos os meios devido às orientações padronizadoras expressas não somente nos conteúdos urbanos do setor do patrimônio sociocultural transmitido, mas também nas origens socioeconômicas dos candidatos ao magistério, em sua formação em escolas normais também padronizadas, na programação dos conteúdos, no material didático, na própria organização das atividades escolares. Se as variáveis intraescolares eram em grande parte semelhantes, as diferenças de rendimento deveriam ser buscadas na maior ou menor variação das denominadas variáveis extraescolares ou, mais precisamente, no maior ou menor grau de integração entre as variáveis intraescolares e as extraescolares.

As deficiências de rendimento do ensino primário definiam-se, nesses termos, como um problema social, como um estado de tensão interna entre forças contrárias: fundamentalmente, o choque de forças urbanas com as condições não urbanas de vida econômica, social e cultural das comunidades rurais e urbanas, bem como das camadas citadinas inferiores. Impunha-se atentar para o caráter inevitável dessa oposição. Com maior ou menor rapidez e intensidade nas diferentes regiões, a sociedade caminhava inevitavelmente para a urbanização, com a progressiva extinção do rural enquanto modalidade rústica de vida. Mas, na época, a população não urbanizada ou semiurbanizada ainda ultrapassava em muito a urbanizada. A expansão da rede de ensino primário estaria alcançando crescentes segmentos de imaturos dos meios rústicos e semiurbanos, reduzindo relativamente a participação dos alunos procedentes dos meios socioculturais das camadas médias e superiores das cidades. Ampliava-se, por conseguinte, o impacto da função urbanizadora no funcionamento da escola.

A fundamentação desse estudo nos trabalhos de Antonio Candido é evidente. Em ambos há a intenção de situar a pesquisa sociológica como subsídio para a atuação do educador. Tudo o que ocorre no processo educativo - no interior da escola e de seus agrupamentos, nas práticas educativas e nas superestruturas ideológicas - é examinado sob a perspectiva da dinâmica da sociedade mais ampla. Ambos focalizam, com especial atenção, as contradições da sociedade e suas decorrências para o processo educativo. Luiz Pereira acolhe as análises 
de Antonio Candido sobre as implicações das diferenças entre a cidade e o campo para a educação. A invasão do rural pelos estilos de vida dos setores urbanos dominantes fundamenta sua explicação das deficiências do rendimento escolar entre as populações rústicas.

Essa mesma adesão às análises e orientações de Antonio Candido está presente na monografia A escola numa área metropolitana (PEREIRA, 1967), apresentada como requisito à conclusão do curso de especialização em Sociologia. Notam-se, aqui também, as expressões dos estudos então realizados sob a orientação de Florestan Fernandes. ${ }^{4}$ Já na apresentação da monografia, Florestan Fernandes assinala que o aspecto mais importante do estudo estava no fato de

[...] traduzir uma mentalidade nova, cada vez mais arraigada nas preocupações dos cientistas sociais brasileiros das gerações ascendentes. Trata-se de delimitar bem um campo de estudos e atacá-lo em profundidade, para adquirir uma autêntica visão científica da realidade. (PEREIRA, 1967) pioneira.

A monografia continha uma significação

Luiz Pereira conseguiu, com os recursos limitados do investigador isolado, selecionar aspectos relevantes de nossa situação educacional, submetê-los a técnicas rigorosas de observação e análise, e explicá-las à luz da teoria sociológica. Com isso ofereceu-nos uma contribuição que faz da sociologia educacional uma disciplina empírica e que nos permite confiar com outro espírito na contribuição que os sociólogos podem dar, seja ao conhecimento positivo da situação educacional brasileira, seja aos planos de reconstrução educacional. (FERNANDES, 1960, p. II)

4 - Ver, especialmente, a bibliografia mobilizada por Luiz Pereira na exposição das características da área e das orientações da população atendida pela escola primária.
E convém atentar também para outro aspecto valorizado nas observações do professor orientador:

[...] sua contribuição toma como unidade de investigação uma comunidade operária de áreas altamente industrializadas do país. Podemos, por isso, contar com um sistema de referência empírica e prática muito produtivo. Como opera a escola primária num bairro proletário? Como é valorizada a educação escolarizada no horizonte cultural de uma população heterogênea e em processo incipiente de classificação profissional na sociedade industrial? Quais são os obstáculos psico-sociais e sócio-culturais que vêm impedindo, no interior das próprias escolas, o ajustamento das instituições escolares às necessidades educacionais do meio social ambiente? (FERNANDES, 1960, p. II)

A monografia subdivide-se em uma introdução, quatro capítulos e as considerações finais. Nessa última parte, definem-se as orientações impressas pelo pesquisador ao estudo da escola. Trata-se, afirma ele, de um estudo de sociologia da educação, esta concebida como o estudo propriamente sociológico do campo educacional. Procurou, pois, evitar a consideração da vida social da escola destacada de todo o contexto que a envolve. E mesmo esse envoltório local - a área servida pela escola e a comunidade metropolitana inclusiva - foi examinado em termos de algumas transformações atuais da comunidade nacional brasileira. Citando Florestan Fernandes, Luiz Pereira afirma, ainda, que:

[...] na tentativa de integrar os resultados desta pesquisa no sistema conceptual da sociologia em geral e no esforço de estudar a escola como algo inserido no contexto mais amplo, recorreu-se ao método de interpretação funcionalista da realidade social. (PEREIRA, 1967, p. 142) 
0 capítulo inicial descreve a área ocupada pelas famílias dos alunos que frequentam a escola investigada. Setor periférico da Região Metropolitana de São Paulo, a área apresenta-se como meio dinâmico de ajustamento de populações migrantes do meio rural aos padrões sociais urbanos e de formação de nova concepção de vida. As características dos habitantes são discriminadas por procedências, experiências profissionais pregressas, novas ocupações e perspectivas de ascensão social no meio urbano, condições de sobrevivência na área, trabalho das mulheres e dos filhos, escolaridade e expectativas de futuro etc. 0 segundo capítulo, dedicado ao estudo da escola primária, acompanha fielmente as indicações de Antonio Candido no artigo sobre a estrutura da escola. A vida coletiva do grupo social escolar é analisada a partir da distinção entre uma ordem de relações institucionalizadas e outras relações espontâneas geradas na sociabilidade própria dos agrupamentos e em boa parte vinculadas ao meio exterior. A ação institucionalizadora do poder público - uma atuação racional legal, explicitada no regimento interno dos grupos escolares determina posições e papéis sociais articulados com vistas à realização dos objetivos estabelecidos para o grupo social escolar. Observa-se, porém, a persistência de concepções, motivações, atitudes e valores tradicionais. Esses componentes motivam comportamentos de resistência à plena racionalização burocrática do agrupamento. 0 terceiro capítulo é dedicado ao estudo das relações entre a escola e a área escolar. Estudam-se as representações da escola pelos seus diferentes segmentos, especialmente nas suas expressões na interação entre os docentes e administradores da escola com os alunos e os moradores. As percepções de moradores e alunos sobre a escola exprimiriam representações patrimonialistas e paternalistas, que impedem a visão da escola como empresa pública de serviços e de seu pessoal docente-administrativo como funcionários burocráticos. 0 mesmo teor de representações estaria presente também na percepção de professores e administradores da escola. A participação numa camada socioeconômica superior à dos moradores favorecia a presença desse mesmo teor de representações entre o pessoal docente e administrativo. 0 sistema idealizado sobre as relações entre a escola e a área escolar articulava-se com a concepção da escola primária como agência missionária e com as representações paternalistas dos papéis definidos por funcionários e professores. Mas essas representações estariam permeadas por pressões geradas nos processos de urbanização, secularização e democratização em curso na região. A ruptura das expectativas tradicionais seria maior por parte dos professores e administradores. 0 quarto capítulo focaliza questões sobre inovação pedagógica e burocratização do magistério. Observa o autor que a escola investigada não atende às expectativas modernizadoras expressas no Regimento Interno dos Grupos Escolares, representando um caso particular de desintegração da escola tradicional, tanto na utilização do tempo, do espaço e do equipamento disponíveis, quanto nas concepções sobre a escola como um todo e sobre os diversos papéis de seus membros.

O magistério primário numa sociedade de classes (PEREIRA, 1963b) dá continuidade, aprofunda e amplia o âmbito de questões já examinadas ou ao menos sugeridas no trabalho anterior. Seleciona para o estudo da profissão do magistério primário algumas características entendidas como especialmente relevantes em sua caracterização. Após um primeiro capítulo introdutório de considerações metodológicas, o segundo capítulo voltava-se para o estudo do magistério como uma ocupação feminina e como um dos principais recursos de acesso da mulher ao mercado de trabalho. Atividade entendida como respeitável em face dos códigos de conduta tradicionais que ainda pesavam sobre o sexo feminino, com duração da jornada diária de trabalho compatível com as atribuições domésticas da mulher, o trabalho na escola possibilitava acrescentar renda às famílias, em geral pressionadas pelas exigências do consumo na sociedade urbana. 0 capítulo seguinte, 
sobre formação profissional e carreira no magistério, descreve os aspectos estruturais do ensino público estadual de São Paulo e, a partir deles, analisa a situação de trabalho então oferecida aos professores primários estudados no município da capital. Reunindo informações estatísticas exaustivas à engenhosa elaboração dos dados disponíveis, o capítulo descreve e analisa a estrutura e o funcionamento do ensino normal, a origens sociais de seus alunos e os padrões de mobilidade dos quadros do magistério. Essa ampla visão panorâmica é aprofundada em seguida, no capítulo sobre a profissionalização do magistério primário. Construída a partir de formulações teóricas de Parsons (1958) sobre orientações societárias e individualistas, e de Mills (1951) sobre modelos artesanais e profissionais de trabalho, uma escala de possíveis aspirações relacionadas ao magistério fornece pistas e oportunidade para fecundas reflexões a propósito de problemas no funcionamento do ensino primário. Os capítulos finais, sobre o magistério primário como setor das classes médias e sobre o magistério primário em São Paulo, completam a monografia. Apoiado nas exaustivas análises de Wright Mills, o texto situa os professores primários nas novas classes médias assalariadas. Nessa época, os professores, na grande maioria, já pertenciam a familias de classe média. Persistiam nas ocupações do magistério

\section{[...] traços ligados à ordem senhorial e tradicionalista, em vias de desaparecimento, ao lado de outros ditados pela necessidade de ajustamento à ordem social de classes ainda em consolidação. (PEREIRA, 1963a, p. 157)}

Coincidia com a formação e o desenvolvimento da sociedade de classes acentuada degradação da ocupação no magistério primário, tanto no plano econômico quanto no social. 0 estudo fundamenta-se em extensa e adequada bibliografia sobre sociedades urbano-industriais; estratificação socioeconômica; mudanças sociais e formação da ordem de classes na sociedade brasileira; situação social da mulher; ocupações e situação de trabalho profissional; magistério como ocupação profissional; funções da educação escolar; e diagnóstico da situação escolar brasileira. Foi concluído e apresentado como tese de doutorado em Sociologia na FFCL da USP, em 1961.

O livro Educação e sociedade: leituras de sociologia da educação foi editado em 1964. As questões da educação continuariam presentes em publicações posteriores: em Trabalho e desenvolvimento no Brasil, concluído em 1965; na coletânea de textos intitulada Desenvolvimento, trabalho e educação, de 1967; e em Estudos sobre o Brasil contemporâneo, de 1971. A dimensão educacional dos processos sociais continuaria presente nos trabalhos de Luiz Pereira durante toda sua atividade intelectual, mas o centro de suas preocupações seria deslocado, primeiro, para o processo de desenvolvimento e, depois, para as diversas faces do modo de produção capitalista no Brasil. Após o ingresso na Cadeira de Sociologia I, em 1963, o referencial teórico de Luiz Pereira apresenta mudanças significativas. 0 livro Trabalho e desenvolvimento no Brasil, publicado em dezembro de 1965, é um seguro indicador dos novos caminhos de seu projeto intelectual. Sua produção intelectual e os cursos de pós-graduação que ministrou posteriormente confirmam as indicações de mudança apontadas nesse estudo. 0 foco das preocupações do pesquisador nos trabalhos seguintes está centralizado nas questões do desenvolvimento. Posteriores reexames da situação educacional contemplam suas leituras de Althusser e, sobretudo, de Gramsci.

\section{Diversificação e enriquecimento do referencial teórico}

As análises de Althusser e de Gramsci, primeiro, e de Bourdieu, depois, tiveram profundas repercussões na produção acadêmica brasileira sobre educação, principalmente a partir de meados da década de 1970. Outros autores, sob diferentes perspectivas, contribuíram 
para o progressivo enriquecimento dos referenciais teóricos da pesquisa em sociologia da educação. Ampliou-se consideravelmente a relação bibliográfica mobilizada nos estudos de sociologia da educação da juventude, dos direitos humanos, da educação popular, dos gêneros, dos movimentos sociais, dos meios de comunicação de massas e de todas as demais especialidades focalizadas pela pesquisa na área.

Esta rápida passagem pelos percursos recentes de nossa disciplina sugere muitas questões para discussão.

Acompanhando a expansão do número de professores e a diversificação dos estudos, aprofundou-se a tendência à especialização da pesquisa entre os integrantes da área. Daí a sugestão de incluirmos nesta série de debates ${ }^{5}$ uma exposição, de cada um dos colegas, sobre o histórico das respectivas especialidades na Faculdade de Educação, o estado dos trabalhos realizados ou em andamento nas diversas modalidades temáticas e as perspectivas de desenvolvimento de tais estudos. A discussão e as reflexões sobre as especialidades poderiam apontar possibilidades e implicações significativas para a sociologia da educação na FEUSP: entre elas, uma possível diluição da disciplina em estudos especializados; o progressivo abandono da escola e dos subgrupos de ensino como objetos de investigação; a dificuldade de inserção da escola e, especialmente, do processo de ensino-aprendizagem nas perspectivas de investigação de especialistas com formação nas ciências sociais; as perspectivas abertas à atuação interdisciplinar das diferentes especialidades etc.

5- Referência aos seminários de pesquisa organizados pela área de Sociologia da Educação do Programa de Pós-Graduação em Educação da FEUSP, ocasião em que o presente texto foi apresentado.
Percebe-se que as perspectivas sociológicas de investigação das realidades sociais alargaram-se e penetraram outros campos das humanidades, inclusive o campo da educação. Como exemplo, encontram-se na FEUSP sociólogos atuando com notável contribuição em diferentes setores de todos os departamentos. Os estreitos limites dos estudos antes demarcados pelas disciplinas da graduação foram progressivamente esgarçados. A ordenação das áreas de pesquisa na pós-graduação exprime bem esse processo. Fica a impressão, porém, de que alguns campos de questões foram quase abandonados em nossas pesquisas: o funcionamento dos subgrupos de ensino; os padrões de interação no grupo social escolar; os valores, os projetos e as expectativas dos agentes que atuam na escola etc. Parece que os caminhos abertos por Antonio Candido e Luiz Pereira não encontraram continuidade em nossos estudos.

Há um bom número de anos, Luiz Antonio Cunha observou que, se no passado o meio universitário foi dominado por uma quantidade relativamente restrita de indivíduos talentosos e, em muitos casos, eruditos, na atualidade essa excepcionalidade de nossos antecessores estaria sendo substituída e compensada (com vantagens?) por equipes de profissionais com formação especializada, trabalhando em grupos, com melhores e maiores recursos. Mas será que estaríamos caminhando com segurança em direção ao aprofundamento das especialidades e, ao mesmo tempo, a algo como uma desejável interdisciplinaridade dos estudos no campo educacional? Será que nesse contexto, concomitantemente à especialização, ocorreria também algo como uma perda de identidade dos estudos antes seguramente identificados como próprios da sociologia da educação? 


\section{Referências}

AZEVEDO, Fernando de. Sociologia educacional. 4. ed. São Paulo: Melhoramentos, 1954.

BEISIEGEL, Celso de Rui. Política e educação popular. Brasilia: Liber Livro, 2008.

DIAS, José Augusto (Org.). Ensino médio e estrutura socioeconômica. Brasília: MEC, 1967.

FÁVERO, Maria de Lourdes; BRITTO, Jader de Medeiros (Orgs.). Luiz Pereira. In: da colônia aos dias atuais. Rio de Janeiro: Editora da UFRJ/MEC/INEP, 2002.

. Dicionário de educadores no Brasil:

FERNANDES, Florestan. Apontamentos sobre os problemas da indução na Sociologia. São Paulo: FFCL/USP, 1954.

. Prefácio. In: PEREIRA, Luiz. A escola numa área metropolitana. São Paulo: FFCL/USP, 1960.

Sobre o trabalho teórico. Transformação, Assis, n. 2, p. 11, 1975.

FERREIRA, Márcia dos Santos. 0 Centro Regional de Pesquisas Educacionais de São Paulo (1956/1961). Dissertação (Mestrado) - Faculdade de Educação, Universidade de São Paulo, São Paulo, 2001.

GURVITCH, Georges. La vocación actual de la sociología. México: FCE, 1953.

HAVIGHURST, Robert James; GOUVEIA, Aparecida Joly. Ensino médio e desenvolvimento. São Paulo: Melhoramentos, 1969.

MARX, Karl. Crítica da economia política. São Paulo: Ed. Flama, 1946.

Idéologie Allemande (1e. partie). Paris: A. Costes, 1937. p. 201-202. (Oeuvres Philosophiques, v. VI)

MILLS, Charles Wright. White Collar: the American middle classes. New York: Oxford University Press, 1951.

PAIVA, Vanilda Pereira. Educação popular e educação de adultos. São Paulo: Loyola, 1973.

. Paulo Freire e o nacionalismo desenvolvimentista. Rio de Janeiro: Civilização Brasileira, 1980.

PARSONS, Talcott. Essays in sociological theory. Glencoe: The Free Press, 1958.

PEREIRA, Luiz. 0 magistério primário metropolitano. Rio de Janeiro: CBPE, 1963a.

. 0 magistério primário numa sociedade de classes. Boletim FFLCH-USP, São Paulo, n. 27, 1963b.

A escola numa área metropolitana. São Paulo: Pioneira Editora, 1967.

. Rendimento e deficiências do ensino primário brasileiro. In: Diagnóstico de uma situação educacional. São Paulo: CRPE "Prof. Queiroz Filho", 1968. (Série Estudos e Documentos, v. 6)

PEREIRA, Luiz; FORACCHI, Marialice M. (Orgs.). Educação e sociedade: leituras de sociologia da educação. São Paulo: Cia. Editora Nacional, 1964.

PINTO, Álvaro Vieira. Ideologia e desenvolvimento nacional. Rio de Janeiro: ISEB, 1956.

RAMOS, Alberto Guerreiro. Introdução aos problemas do Brasil. Rio de Janeiro: ISEB, 1956.

. A redução sociológica. Rio de Janeiro: ISEB, 1958.

RIBEIRO, José Querino. Pequenos estudos sobre grandes problemas educacionais. São Paulo: FFCL/USP, 1952. 
SOUZA, Antonio Candido. As diferenças entre o campo e cidade e o seu significado para a educação. Pesquisa e Planejamento, São Paulo, n. 1, 1957.

A estrutura da escola. In: PEREIRA, Luiz; FORACCHI, Marialice M. (Orgs.). Educação e sociedade: leituras de sociologia da educação. São Paulo: Cia. Editora Nacional, 1964.

TEIXEIRA, Anísio. Educação não é privilégio. São Paulo: Cia. Editora Nacional, 1957.

VIDAL, Diana Gonçalves (Org.). Na batalha da educação: correspondência entre Anísio Teixeira e Fernando de Azevedo (19291971). Bragança Paulista: EDUSF, 2000.

ZNANIECKI, Florian. Organisation sociale et institutions. In: GURVITCH, Georges; MOORE, Wilbert (Orgs.). La sociologie au XXe siècle. Paris: Presses Universitaires de France, 1947.

Recebido em: 11.10.2012

Aprovado em: 09.11.2012

Celso de Rui Beisiegel é professor da Faculdade de Educação da Universidade de São Paulo (USP). Possui graduação em Ciências Sociais (1958), mestrado em Sociologia (1964) e doutorado em Sociologia pela USP (1972). Também na USP, exerceu a chefia do Departamento de Filosofia da Educação e Ciências da Educação e a diretoria da Faculdade de Educação, além de ter sido pró-reitor de graduação entre 1990 e 1993. 